Research Article

\title{
Nondestructive Testing of Advanced Concrete Structure during Lifetime
}

\author{
Lubos Pazdera, Libor Topolar, Jaroslav Smutny, and Kristyna Timcakova
}

Brno University of Technology, Veveri 95, 60200 Brno, Czech Republic

Correspondence should be addressed to Lubos Pazdera; pazdera.l@fce.vutbr.cz

Received 19 September 2014; Revised 1 December 2014; Accepted 18 December 2014

Academic Editor: Yan Yang

Copyright ( 2015 Lubos Pazdera et al. This is an open access article distributed under the Creative Commons Attribution License, which permits unrestricted use, distribution, and reproduction in any medium, provided the original work is properly cited.

\begin{abstract}
The paper reports on measurements and analysis of the measurements during hardening and drying of specimens using selected acoustic nondestructive testing techniques. An integrated approach was created for better understanding of the relations between the lifetime cycle and the development of the mechanical properties of concrete. Acoustic emission, impact echo, and ultrasonic techniques were applied simultaneously to the same mixtures. These techniques and results are presented on alkali-activated slag mortars. The acoustic emission method detects transient elastic waves within the material, caused by the release of cumulated stress energy, which can be mechanical, thermal, or chemical. Hence, the cause is a phenomenon which releases elastic energy into the material, which then spreads in the form of an elastic wave. The impact echo method is based on physical laws of elastic stress wave propagation in solids generated by mechanical impulse. Ultrasonic testing is commonly used to find flaws in materials or to assess wave velocity spreading.
\end{abstract}

\section{Introduction}

Concrete is one of the most widely used building materials with global consumption rate approaching 25 gigatonnes (Gt) per year, which corresponds to over four tones per person annually [1]. Concrete is basically a mixture of aggregates and paste. The aggregates are sand and gravel or crushed stone, and the paste is water and usually Portland cement [2]. Alkali-activated concrete is a new generation of alternative building materials; the main difference from traditional Portland cement concrete is the use of a relatively alkalirich, clinker-free binder matrix such as alkali-activated slag or geopolymer. In comparison to the conventional concretes, the production of alkali-activated concretes is associated with low energy consumption and low $\mathrm{CO}_{2}$ emission, along with the potential to reach high mechanical strength at early ages of curing, high stability in aggressive environments, resistance to high temperature, and so forth [3]. Concrete is known as a heterogeneous material containing various constituents (sand, aggregates, cement, etc.). The dimensions and geometry of the constituents are different and their locations are randomly distributed in the body of concrete.
Hence, it is highly possible that defects and damage occur in concrete even before it is mechanically loaded [4]. These methods are developed as well for homogeneous materials as metals. Their applications for heterogeneous structures are not simple and their development still continues [5]. Since concrete is the most popular building material, its development is necessary to monitor its properties during its lifetime. The strength properties of concrete in a structure can be normally obtained by testing samples acquired from the actual structure. However, this technique is destructive. Therefore, a number of nondestructive tests have been devised and developed over the years to assess the quality of concrete in structures [6].

The microstructure of the developed construction material was examined during hydration and drying processes by means of embedded acoustic emission monitoring method [7].

Alkali-activated aluminosilicates mortars were produced from recycled bricks, water glass, and commercial grade caustic soda flakes. The solid part of the mortar was a mixture of recycled bricks and caustic soda powders. The liquid part consisted of diluted water glass [8]. 
TABLE 1: The mixture composition.

\begin{tabular}{lc}
\hline Components & Amount \\
\hline Grained granulated blast furnace slag & $0.45 \mathrm{~kg}$ \\
Sodium silicate (water glass) & $0.18 \mathrm{~kg}$ \\
Silica sand & $1.35 \mathrm{~kg}$ \\
Water & $0.095 \mathrm{~L}$ \\
\hline
\end{tabular}

\section{Materials and Methods}

The composition of the tested mixture is listed in Table 1. Alkali-activated slag slurry was poured into steel moulds, the length of which was $160 \mathrm{~mm}$ and cross-section $40 \mathrm{~mm}$ $\times 40 \mathrm{~mm}$. After 24 hours the samples were demoulded and immersed in water for another two, six, or 28 days.

When a material is subjected to loading and when cracks occur, which lead to a sudden release of strain energy from the material, an elastic stress wave is created which travels from the point of origin to the boundary of the material [9]. These discrete acoustic waves produced by each microcrack generate a unique transient wave and the development of this zone can be detected. The stress wave is then measured by the transducers in order to obtain suitable information about stress threshold of the material [10].

The acoustic emission method seems to be very useful. The method examines the efficiency of "natural" autogenous crack healing of concrete. Autonomous crack healing in concrete due to encapsulated healing agents is investigated. Both mechanical properties and acoustic emission analysis are used to evaluate the autonomous crack healing efficiency [11]. In this study, the acoustic emission monitoring system, Dakel, with piezoelectric sensors was applied for detecting acoustic emission signal. Universal measurement and diagnostic system DAKEL-XEDO is a modular system with acoustic emission parameters evaluation unit XEDO-AE.

The impact echo is an acoustic method associated with frequency analysis of the short-time response of the material due to an impact load [12]. It was originally developed to evaluate the integrity of plate-like structures by detecting the location and extent of flaws within them [13]. The technique of the impact echo method involves using a transient stress pulse into the test object by mechanical impact and monitoring the surface displacements caused by the arrival of reflections of the pulse from internal defects and external boundaries. Recorded displacement waveforms are analyzed in the frequency domain [14]. A short-time mechanical impulse with a hammer blow was applied for the impact echo method to the surface of the specimen during the test and the response was recorded by piezoelectric sensors. The HandyScope HS3, powerful $100 \mathrm{MS} / \mathrm{s}, 16$ bits, USB oscilloscope, which can be also used as a spectrum analyser, data logger, or protocol analyser, was used to record the impulse response.

The internal structure of concrete is complex because the structure is heterogeneous at both the microscopic and macroscopic levels. This complexity makes the ultrasonic waves in concrete highly irregular and hinders nondestructive evaluation [15] through other conventionally

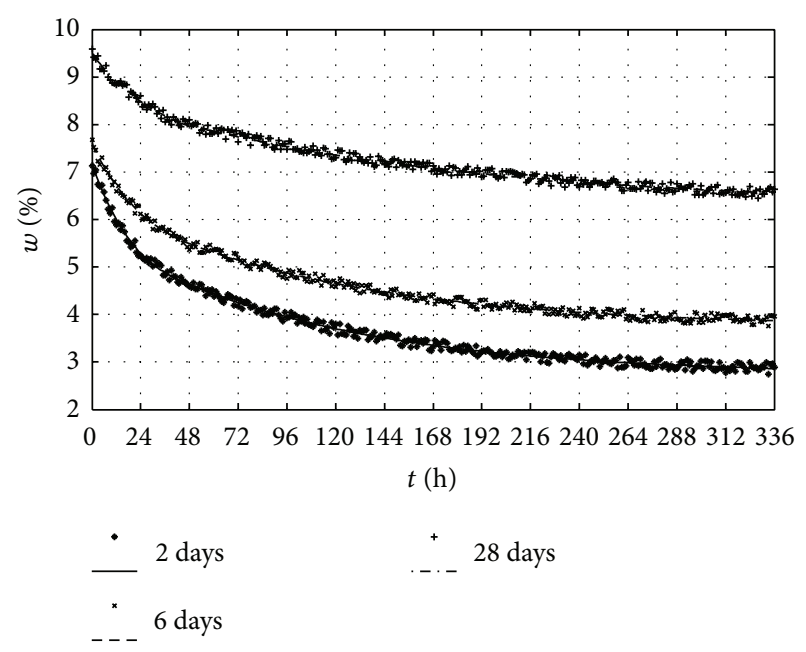

FIGURE 1: Relative loss in weight.

used methods. The ultrasonic nondestructive testing method enables detection of cracks and other discontinuities. Mechanical properties such as the dynamic modulus of elasticity, the damage, and its fracture strength can also be found [16]. Ultrasonic testing enables effective spreading of low amplitude waves through the material, to measure the time of spreading and the change in intensity for a given distance. In spite of the development of test techniques and equipment, using nondestructive testing for inspecting concrete brings many difficulties [17]. Compared to metal and metal-based materials, nondestructive testing of concrete is a relatively new discipline [18].

Measuring equipment PUNDIT (portable ultrasonic nondestructive digital indicating tester) is used for ultrasound measuring of spreading speed of a pulse of ultrasonic longitudinal stress waves. The instruments have a time resolution of $0.1 \mu \mathrm{s}$. For the tests of concrete, the coefficient of variation for repeated measurements at the same location is $2 \%[19,20]$.

\section{Results and Discussion}

Evaluation during spontaneous drying was focused on the relative loss of weight, thus measuring of specimens weighting, ultrasonic velocity, impact echo response and acoustic emission activity were used [21-23].

Some characteristics, that is, loss in weight, ultrasound velocity, and maximal frequency, were approximated by one or two exponential curves by

$$
f(t)=p_{1} \cdot e^{-p_{2} \cdot t}+p_{3},
$$

where $f(t)$ is approximated parameters (relative loss factor, $w$, ultrasound velocity, $v$, and maximal frequency component, $f), p_{1}, p_{2}, p_{3}$ are function parameters, and $t$ is time. In Figures 1 to 3 markers are measured values and lines are approximated curves by exponential functions (1).

Relative loss in weight decreases in time is given in Figure 1. Decreasing relative loss in the first 48 hours is similar in all used samples. However, after 48 hours the loss is 
TABLE 2: Function parameters $-f(t)=p_{1} \cdot \exp \left(-p_{2} \cdot t\right)+p_{3}$.

\begin{tabular}{|c|c|c|c|c|}
\hline$f(t)$ & Days & $p_{1}$ & $p_{2}$ & $p_{3}$ \\
\hline \multirow{3}{*}{ Impact echo frequency $[\mathrm{kHz}]$} & 2 & $3.7 \mathrm{kHz}$ & $0.0128 \mathrm{~h}^{-1}$ & $5.9 \mathrm{kHz}$ \\
\hline & 6 & $3.0 \mathrm{kHz}$ & $0.0164 \mathrm{~h}^{-1}$ & $7.4 \mathrm{kHz}$ \\
\hline & 28 & $3.4 \mathrm{kHz}$ & $0.0278 \mathrm{~h}^{-1}$ & $8.4 \mathrm{kHz}$ \\
\hline \multirow{3}{*}{ Ultrasound velocity $\left[\mathrm{mm} \cdot \mu \mathrm{s}^{-1}\right]$} & 2 & $1.7 \mathrm{~mm} \cdot \mu \mathrm{s}^{-1}$ & $0.0128 \mathrm{~h}^{-1}$ & $2.0 \mathrm{~mm} \cdot \mu \mathrm{s}^{-1}$ \\
\hline & 6 & $1.4 \mathrm{~mm} \cdot \mu \mathrm{s}^{-1}$ & $0.0127 \mathrm{~h}^{-1}$ & $2.5 \mathrm{~mm} \cdot \mu \mathrm{s}^{-1}$ \\
\hline & 28 & $1.0 \mathrm{~mm} \cdot \mu \mathrm{s}^{-1}$ & $0.0105 \mathrm{~h}^{-1}$ & $3.0 \mathrm{~mm} \cdot \mu \mathrm{s}^{-1}$ \\
\hline \multirow{3}{*}{ Relative loss in weight (the first $48 \mathrm{~h}$ ) [\%] } & 2 & $2.9 \%$ & $0.0446 \mathrm{~h}^{-1}$ & $4.3 \%$ \\
\hline & 6 & $2.6 \%$ & $0.0348 \mathrm{~h}^{-1}$ & $5.0 \%$ \\
\hline & 28 & $2.1 \%$ & $0.0275 \mathrm{~h}^{-1}$ & $7.4 \%$ \\
\hline \multirow{3}{*}{ Relative loss in weight (after $48 \mathrm{~h}$ ) [\%] } & 2 & $3.0 \%$ & $0.0095 \mathrm{~h}^{-1}$ & $2.8 \%$ \\
\hline & 6 & $2.7 \%$ & $0.0090 \mathrm{~h}^{-1}$ & $3.8 \%$ \\
\hline & 28 & $2.3 \%$ & $0.0064 \mathrm{~h}^{-1}$ & $6.5 \%$ \\
\hline
\end{tabular}

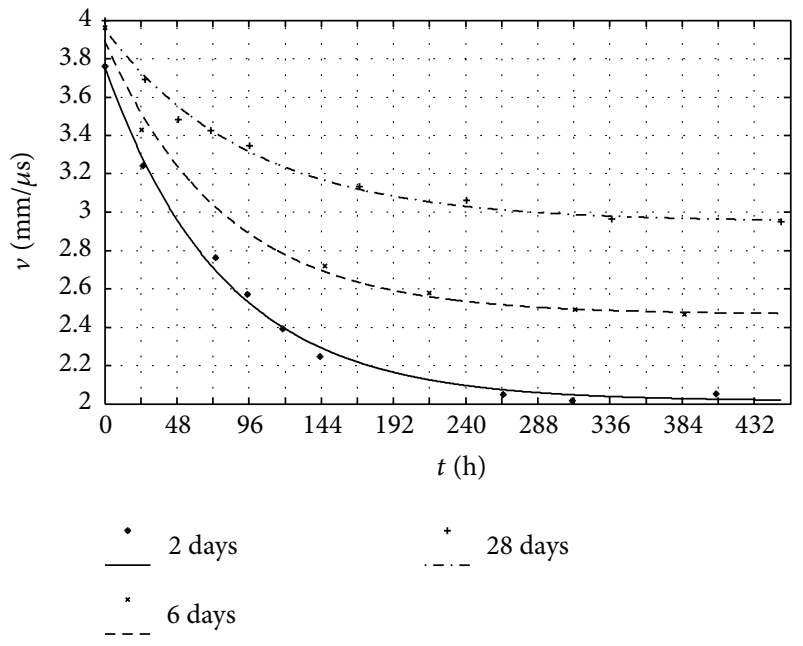

FIGURE 2: Ultrasound velocity.

decreased rapidly in the sample after 2 days of curing, and it is the slowest in the sample after 28 days of curing as is written in Table 2 (parameter $p_{2}$ ).

Ultrasound velocity is decreased approximately by the exponential function. After 18 days, the ultrasound velocities of specimens are similarly constant (Figure 2 ) and their values are different according to the curing time.

Ultrasound velocity is decreased approximately by the exponential function very closely. After 18 days the ultrasound velocities of specimens are similarly constant (Figure 2) and their values are different by the currying time.

Dynamic modulus of elasticity is dependent on frequency and its values are increasing with ultrasound velocity; therefore, more curing samples acquire higher values (Table 2 , parameter $p_{3}$ ).

Shift of the dominant frequency during the drying process causes decreasing frequency as it is displayed in Figure 3. All three graphs in Figures 1 to 3 show different behaviour of three different curing samples with three different curves. Thus, the longer the curing, the better the properties of the samples.

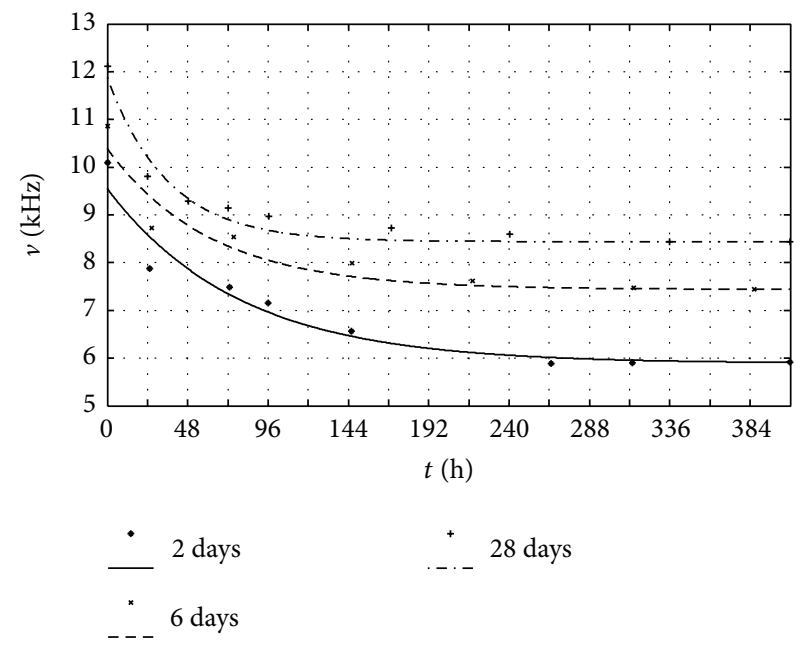

FIGURE 3: Maximal frequency component of impact echo testing.

Acoustic emission activities determine two different parts in the whole samples, evaporation and structural changes in the first part, and determine generating cracks during the second part as is shown in Figure 4. The first part is 6 hours longer for samples after 2 days of curing, 8 hours for 6 days of curing, and 13 hours for 28 days of curing samples. Very slow increase of acoustic emission activity of second part is after 28 days of curing samples. However, acoustic emission activity significantly increases after 2 days of curing the sample.

\section{Conclusion}

The paper has presented a combined experimental approach of the study of setting and hardening of alkali-activated slag. Measurements of ultrasonic velocities, acoustic emission, and impact echo were performed at the same time.

It is assumed that most of the changes after evaporation can be attributed to crack deformations. Therefore, the main process leading to determination of alkali-activated slag binder is associated with drying shrinkage [24]. 


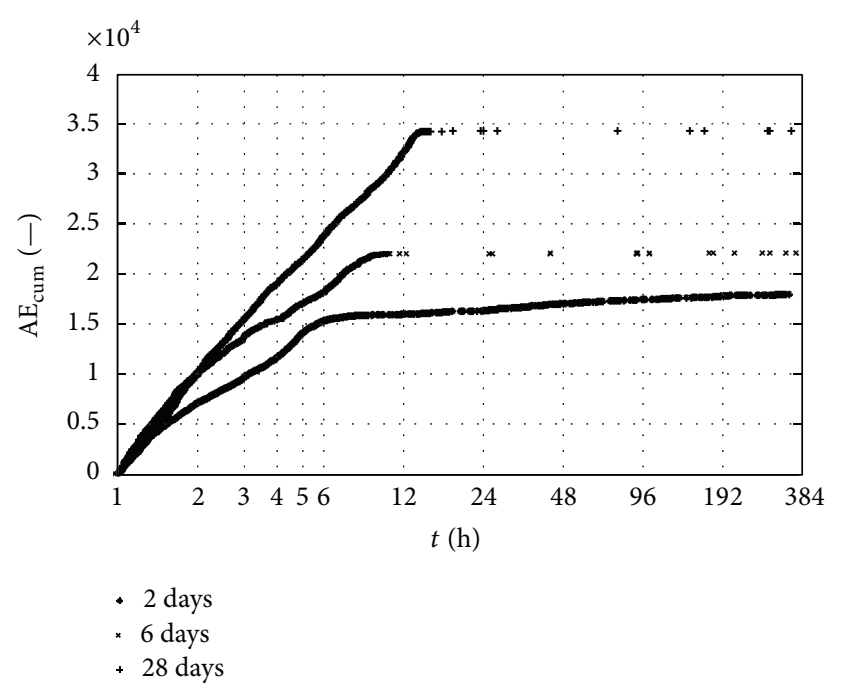

FIgURE 4: Cumulative acoustic emission activity.

Comparing these methods concluded that more accurate information about the monitoring process of alkali-activated slag is obtained by combination of these methods.

\section{Conflict of Interests}

The authors declare that there is no conflict of interests regarding the publication of this paper.

\section{Acknowledgment}

This paper was elaborated with the financial support of the European Union's “Operational Programme Research and Development for Innovations," no. CZ.1.05/2.1.00/03.0097, as an activity of the regional Centre AdMaS "Advanced Materials, Structures and Technologies" and GACR 13-70188S.

\section{References}

[1] A. Petek Gursel, E. Masanet, A. Horvath, and A. Stadel, "Lifecycle inventory analysis of concrete production: a critical review," Cement and Concrete Composites, vol. 51, pp. 38-48, 2014.

[2] C. R. Gagg, "Cement and concrete as an engineering material: an historic appraisal and case study analysis," Engineering Failure Analysis, vol. 40, pp. 114-140, 2014.

[3] S. A. Bernal, R. Mejía de Gutiérrez, A. L. Pedraza, J. L. Provis, E. D. Rodriguez, and S. Delvasto, "Effect of binder content on the performance of alkali-activated slag concretes," Cement and Concrete Research, vol. 41, no. 1, pp. 1-8, 2011.

[4] A. A. Shah and Y. Ribakov, "Non-linear ultrasonic evaluation of damaged concrete based on higher order harmonic generation," Materials and Design, vol. 30, no. 10, pp. 4095-4102, 2009.

[5] T. Sakagami and S. Kubo, "Development of a new nondestructive testing technique for quantitative evaluations of delamination defects in concrete structures based on phase delay measurement using lock-in thermography," Infrared Physics \& Technology, vol. 43, no. 3-5, pp. 311-316, 2002.
[6] R. L. Al-Mufti and A. N. Fried, "The early age non-destructive testing of concrete made with recycled concrete aggregate," Construction and Building Materials, vol. 37, pp. 379-386, 2012.

[7] Y. Lu, J. Zhang, and Z. Li, "Study on hydration process of early-age concrete using embedded active acoustic and noncontact complex resistivity methods," Construction and Building Materials, vol. 46, pp. 183-192, 2013.

[8] S. B. H. Farid, "Practicable activated aluminosilicates mortar," Ceramics International, vol. 40, no. 9, part B, pp. 15027-15032, 2014.

[9] K. Kovler and N. Roussel, "Properties of fresh and hardened concrete," Cement and Concrete Research, vol. 41, no. 7, pp. 775792, 2011.

[10] P. G. Ranjith, D. Jasinge, J. Y. Song, and S. K. Choi, "A study of the effect of displacement rate and moisture content on the mechanical properties of concrete: use of acoustic emission," Mechanics of Materials, vol. 40, no. 6, pp. 453-469, 2008.

[11] K. van Tittelboom, N. de Belie, F. Lehmann, and C. U. Grosse, "Acoustic emission analysis for the quantification of autonomous crack healing in concrete," Construction and Building Materials, vol. 28, no. 1, pp. 333-341, 2012.

[12] C.-C. Cheng, Y. Lin, C.-M. Hsiao, and H.-C. Chang, "Evaluation of simulated transfer functions of concrete plate derived by impact-echo method," NDT \& E International, vol. 40, no. 3, pp. 239-249, 2007.

[13] X. Lu, Q. Sun, W. Feng, and J. Tian, "Evaluation of dynamic modulus of elasticity of concrete using impact-echo method," Construction and Building Materials, vol. 47, pp. 231-239, 2013.

[14] M.-T. Liang and P.-J. Su, "Detection of the corrosion damage of rebar in concrete using impact-echo method," Cement and Concrete Research, vol. 31, no. 10, pp. 1427-1436, 2001.

[15] I. N. Prassianakis and N. I. Prassianakis, "Ultrasonic testing of non-metallic materials: concrete and marble," Theoretical and Applied Fracture Mechanics, vol. 42, no. 2, pp. 191-198, 2004.

[16] A. Benouis and A. Grini, "Estimation of concrete's porosity by ultrasounds," Physics Procedia, vol. 21, pp. 53-58, 2011.

[17] S. Iyer, S. K. Sinha, M. K. Pedrick, and B. R. Tittmann, "Evaluation of ultrasonic inspection and imaging systems for concrete pipes," Automation in Construction, vol. 22, pp. 149164, 2012.

[18] F. Benmeddour, G. Villain, O. Abraham, and M. Choinska, "Development of an ultrasonic experimental device to characterise concrete for structural repair," Construction and Building Materials, vol. 37, pp. 934-942, 2012.

[19] S. A. Abo-Qudais, "Effect of concrete mixing parameters on propagation of ultrasonic waves," Construction and Building Materials, vol. 19, no. 4, pp. 257-263, 2005.

[20] M. M. Ranjbar, M. H. Beygi, I. M. Nikbin, M. Rezvani, and A. Barari, "Evaluation of the strength variation of normal and lightweight self-compacting concrete in full scale walls," Materiali in Tehnologije, vol. 45, no. 6, pp. 571-577, 2011.

[21] M. Tasić, Z. Andić, A. Vujović, and P. Jovanić, "Analysis of the process of crystallization of continuous cast special brass alloys with the acoustic emission," Materiali in Tehnologije, vol. 44, no. 6, pp. 397-401, 2010.

[22] P. Rovnaník, P. Bayer, and P. Rovnaníková, "Characterization of alkali activated slag paste after exposure to high temperatures," Construction and Building Materials, vol. 47, pp. 1479-1487, 2013. 
[23] L. Pazdera and L. Topolar, "Application acoustic emission method during concrete frost resistance," Russian Journal of Nondestructive Testing, vol. 50, no. 2, pp. 127-131, 2014.

[24] L. Topolar, L. Pazdera, and P. Cikrle, "Acoustic emission monitoring during static modulus elasticity test of concrete specimen," Applied Mechanics and Materials, vol. 486, pp. 267$272,2014$. 

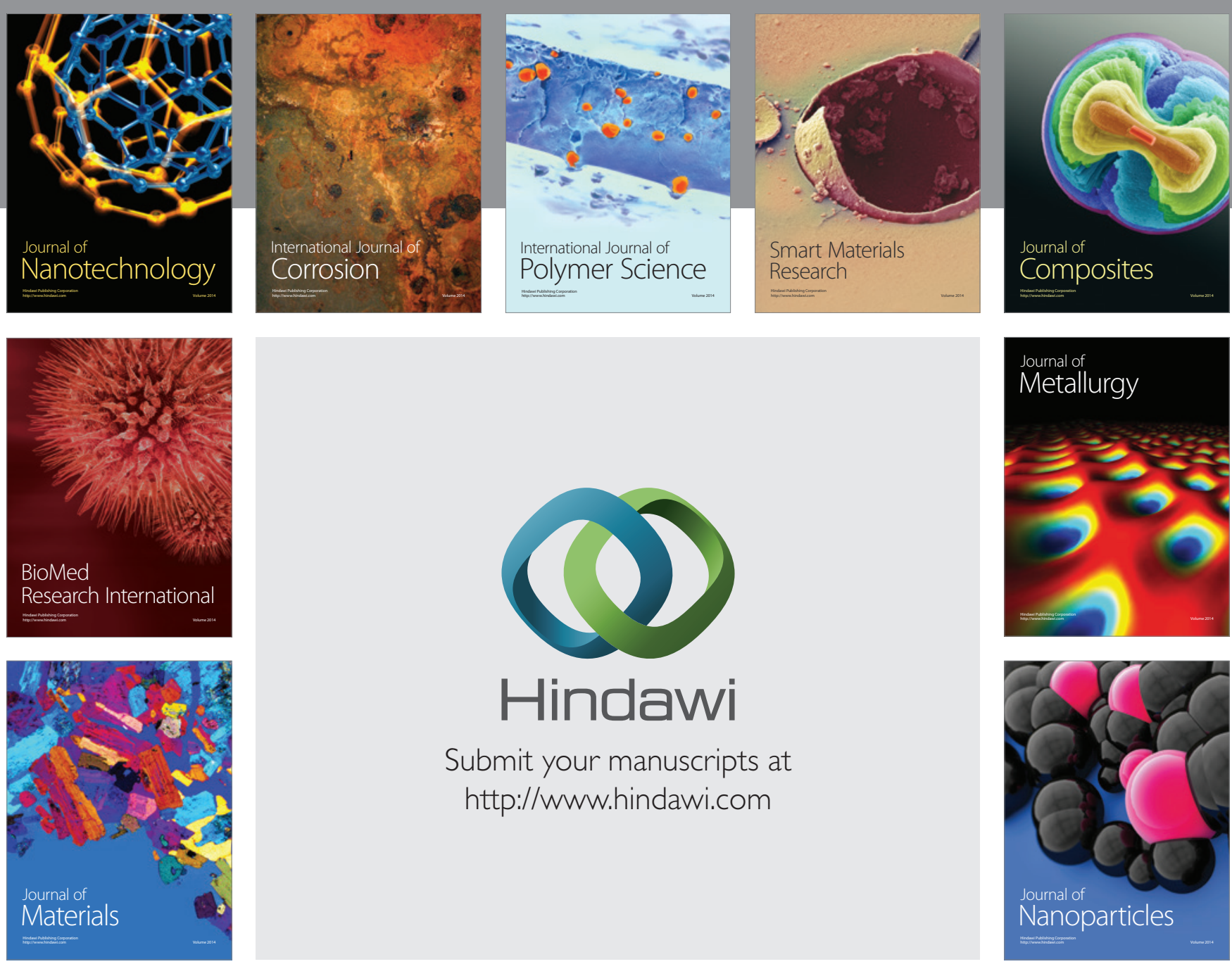

Submit your manuscripts at http://www.hindawi.com
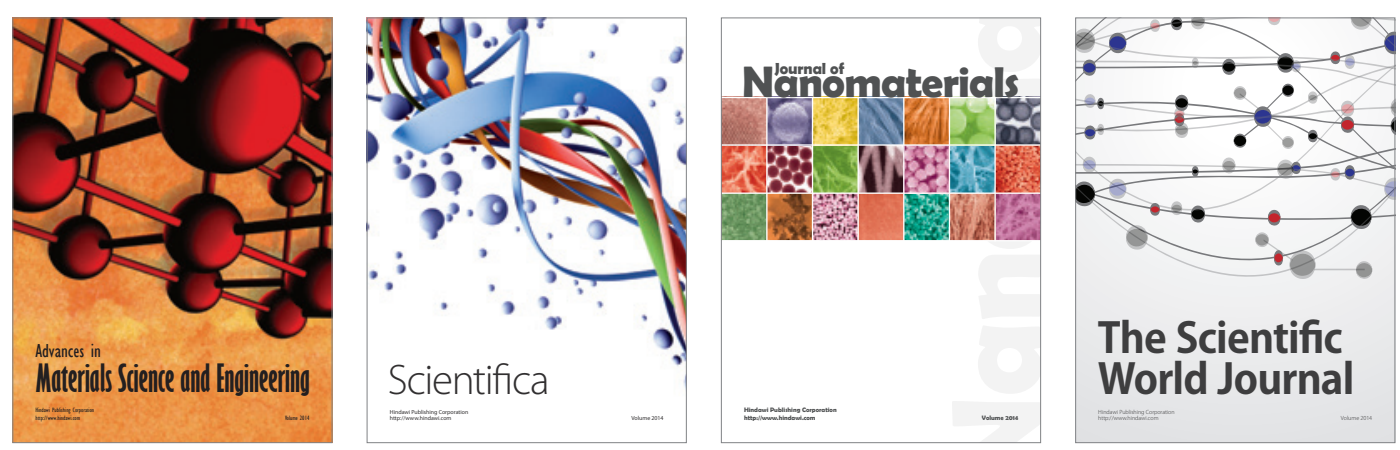

\section{The Scientific World Journal}
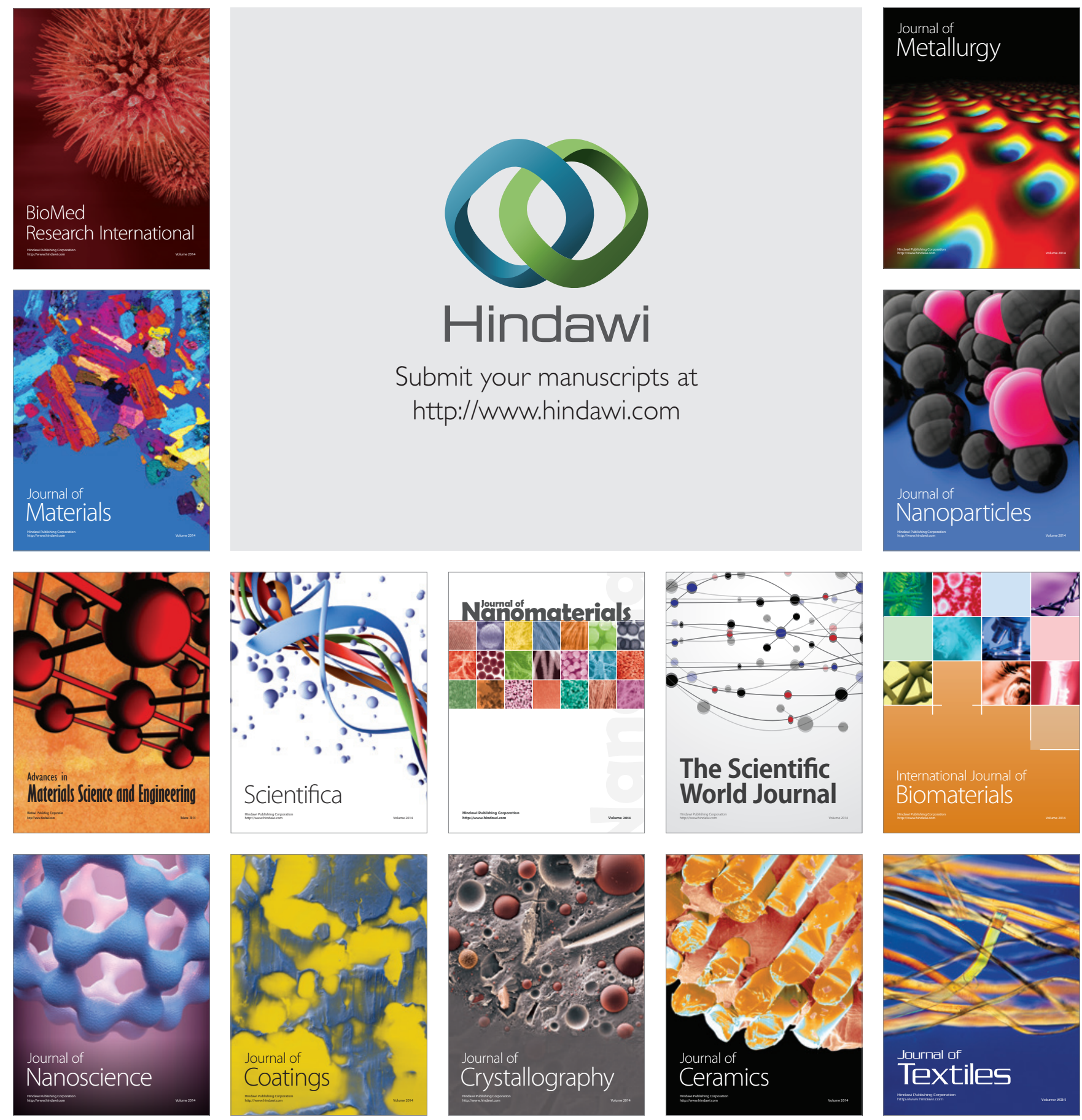